\title{
Marine Microbiome as a Source of Antimalarials
}

\author{
Peter J. McCarthy ${ }^{1}$, Bracken F. Roberts ${ }^{2}$, Abigail Carbonell ${ }^{2}{ }^{\mathbb{D}}$, Jill Roberts ${ }^{1}$, Amy E. Wright ${ }^{1}$ \\ and Debopam Chakrabarti ${ }^{2, *(\mathbb{D})}$ \\ 1 Harbor Branch Oceanographic Institute, Florida Atlantic University, Fort Pierce, FL 34946, USA \\ 2 Division of Molecular Microbiology, Burnett School of Biomedical Sciences, University of Central Florida, \\ Orlando, FL 32826, USA \\ * Correspondence: dchak@ucf.edu; Tel.: +1-407-882-2256
}

Received: 21 May 2019; Accepted: 9 July 2019; Published: 13 July 2019

\begin{abstract}
It is important to discover novel antimalarial pharmacophores because of the widespread emergence of Plasmodium falciparum isolates resistant to the available drugs. Secondary metabolites derived from microbes associated with marine invertebrates are a valuable resource for the discovery of novel drug leads. However, the potential of marine microbes as a source of antimalarials has not been explored. We investigated the promise of marine microorganisms for the production of antimalarial activities by testing 2365 diverse microbial extracts using phenotypic screening of a multidrug resistant chloroquine resistant $P$. falciparum strain. We conducted counter screening against mammalian cells for the 317 active extracts that exhibited more than $70 \%$ inhibition at $1 \mu \mathrm{g} / \mathrm{mL}$. The screen identified 17 potent bioactive leads from a broad range of taxa. Our results establish that the marine microbiome is a rich source of antiplasmodial compounds that warrants in depth exploration.
\end{abstract}

Keywords: Marine Microbe; Malaria; Plasmodium; Antimalarials; Harbor Branch

\section{Introduction}

Over $40 \%$ of the global population currently resides in regions with malaria transmission. There were 219 million clinical cases of malaria in 2017 causing 435,000 deaths [1] and the available drugs against malaria are rapidly losing efficacy because of rapid emergence to resistance. Even artemisinin combination therapy, which is the recommended treatment for malaria in the disease endemic countries, is showing an alarming spread of resistance in wide areas of Southeast Asia [2,3]. Given this alarming situation for malaria treatment options, it is important to discover new chemical leads for the next generation of malaria therapeutics.

Historically, natural products have been an important source for the discovery of new drug leads. Of 1562 approved new drugs during the period 1981-2014, 930 (59.5\%) were from natural products, natural product-derived, or natural product-inspired compounds [4]. Natural products have been a particularly useful source for the discovery of anticancer and anti-infective agents including antimalarial agents such as quinine. More recently, the artemisinins, derived from the sweet wormwood that was originally used in Chinese herbal medicines, have become a frontline treatment for drug-resistant malaria.

While the majority of the approved natural products and natural product-derived chemical entities are derived from terrestrial habitats, the marine environment remains largely unexplored. This represents an opportunity for the identification of novel compounds with therapeutic properties from marine biodiversity. Although marine invertebrates and algae have been the primary target for the discovery of new therapeutics, the focus of marine biotechnology has now shifted towards marine microbes $[5,6]$. It is believed that many compounds originally isolated from marine invertebrates actually originate from marine bacteria [5]. The ocean surface layer typically contains $10^{5}$ microbial 
cells per $\mathrm{ml}$ [7]. Some marine sponges, termed high microbial abundance sponges, contain large populations of associated microbes at densities of $10^{8}-10^{10} / \mathrm{g}$ sponge tissue that can comprise up to $20-30 \%$ of the sponge's biomass [8] and there is growing evidence that these microbial populations play key roles in sponge metabolism including the production of natural products $[9,10]$. One of the first examples of a sponge metabolite that has since been shown to be produced by a cultivated microorganism is manzamine $\mathrm{A}$, an antimalarial compound that is produced by a sponge-associated actinomycete [11,12]. Additional antimalarial compounds produced by marine microbes include 2-undecyl-4-quinolone from a sponge-associated Pseudomonas [13], and calothrixins A and B from the cyanobacterium Calothrix [14]. In spite of the enormous potential of the marine microbiome as a source for novel chemotypes, its utility for discovery of novel antimalarials has not been thoroughly exploited.

The microbiology group at Harbor Branch Oceanographic Institute (HBOI) has an on-going program studying the microbial population associated with deep-water invertebrates. As part of this research, a focus has been the development of novel cultivation methods that, in certain cases, have improved recovery from environmental samples by over 300\% [15]. This ongoing research project has resulted in the establishment of a substantial culture collection of heterotrophic marine microbes, the Harbor Branch Marine Microorganism Culture Collection (HBMMCC, Table 1), which now contains over 19,000 isolates that have only recently become the subject of a focused screening program. We have determined the taxonomic affiliation of $>2290$ heterotrophic eubacterial isolates in the HBMMCC using restriction fragment linked polymorphism (RFLP) and sequence analyses of the 16S SSU rRNA gene $[16,17]$. The subset of the HBMMCC that was used for the taxonomic study contains 233 different operational taxonomic units (OTUs) from six major eubacterial clades. SSU rRNA sequences of 19 OTUs were $\leq 93 \%$ similar to the closest sequence match in the GenBank database, indicating the likely discovery of novel microbial taxa. Furthermore, the HBMMCC contains microbes previously described as uncultured, including sponge-specific symbionts. The surveyed actinomycetes indicated that most of these isolates represent new species when compared with those found in GenBank (similarity $<97 \%$ ). The HBMMCC also includes over 2000 fungal isolates including some genera commonly found in many environments, nonetheless, the collection includes more unusual isolates such as Warcupiella and a fungus isolated from the sponge Forcepia with the closest GenBank match having only 91\% sequence similarity to Penicillium sp. It is well-documented that marine isolates of common fungi, such as those of the genera Penicillium and Aspergillus, are known to produce novel metabolites $[9,18]$.

Table 1. Taxonomic affiliation of isolates contained in the HBOI Marine Microbial Culture Collection.

\begin{tabular}{ccc}
\hline Taxonomic Affiliation & Number of Isolates & Number Isolated from Sponges \\
\hline Actinomycetes & 1037 & 416 \\
Other bacteria & 16,129 & 11,281 \\
Fungi & 2074 & 1427 \\
\hline
\end{tabular}

Here we report the screening of the Harbor Branch Marine Microorganism collection for antiplasmodial activities.

\section{Materials and Methods}

\subsection{Fermentation}

Microbial isolates were cultured in SYZ medium (15 g soluble starch, $2 \mathrm{~g}$ yeast extract, $4 \mathrm{~g}$ NZ-amine, $2 \mathrm{~g}$ dextrose, $750 \mathrm{~mL}$ artificial sea water, $250 \mathrm{~mL}$ deionized water) and KP medium (2 $\mathrm{g}$ kelp powder, $2 \mathrm{~g}$ fish meal, $4 \mathrm{~mL}$ super fish emulsion, $5 \mathrm{~g}$ soluble starch, $1000 \mathrm{~mL}$ artificial sea water; $30 \mathrm{~mL}$ dispensed into flasks containing $60 \mathrm{mg}$ chitosan) using the following two growth conditions. Fermentations were performed primarily in shake cultures ( $210 \mathrm{rpm}, 7-14$ days, $25^{\circ} \mathrm{C}$ ), however a small subset of the isolates were also grown in static cultures $\left(\sim 21\right.$ days, $\left.25^{\circ} \mathrm{C}\right)$. All liquid fermentations were performed at the $30 \mathrm{~mL}$ scale using $125 \mathrm{~mL}$ Erlenmeyer flasks. 
An alternate fermentation method used moistened rice as a substrate for the growth of fungi. Rice ( $25 \mathrm{~g}$ ) was placed in a $125 \mathrm{~mL}$ flask and soaked overnight in $100 \mathrm{~mL}$ deionized water. The water was then decanted off and the flask capped. Autoclaved flasks were inoculated from a $10 \mathrm{~mL} \mathrm{SYZ}$ liquid culture and incubated at $25^{\circ} \mathrm{C}$ for $\sim 21$ days. At harvest, the cultures were freeze-dried prior to extraction.

\subsection{Extraction}

At harvest, a 1:1 mixture of Amberlite ${ }^{\circledR}$ XAD-16 (Sigma-Aldrich, St Louis, MO, USA) and Diaion ${ }^{\circledR}$ HP20 (Sigma-Aldrich, St Louis, MO) resins was added to liquid cultures and mixed for $2 \mathrm{~h}$ on a rotary shaker. Resins were added in order to extract a broad range of metabolites from the fermentation broth. The mixture of cell mass and resins were collected by filtration through Celite ${ }^{\circledR} 545$ (Acros Organics, Thermo Fisher Scientific, Waltham, MA, USA). The cell residue and resin was washed $3 \times$ with $50 \mathrm{~mL}$ deionized water, to remove broth components and salts, and was then extracted sequentially by the addition of methanol $(50 \mathrm{~mL})$ and dichloromethane $(50 \mathrm{~mL})$.

Extraction of moistened rice fermentations was performed using an Accelerated Solvent Extractor (ASE 100, Dionex, Salt Lake City, UT, USA). Freeze-dried samples were packed into $100 \mathrm{~mL}$ extraction cells and extracted at $100{ }^{\circ} \mathrm{C}$ by the sequential addition of heptane, ethyl acetate:ethanol (1:1), and methanol. Each solvent was added twice with a soak time for each addition of $21 \mathrm{~min}$. The extraction system was designed to extract chemicals with a broad polarity range.

All extracts were concentrated under reduced pressure and subsamples $(200 \mu \mathrm{g})$ of each were submitted for biological evaluation.

\subsection{Plasmodium in Vitro Culture}

Plasmodium falciparum chloroquine resistant Dd2 was maintained in a modified Trager and Jensen method [19] in RPMI 1640 medium with L-glutamine (Invitrogen, Carlsbad, CA, USA) and supplemented with $25 \mathrm{mM}$ HEPES, pH 7.4, $26 \mathrm{mM} \mathrm{NaHCO}_{3}, 2 \%$ dextrose, $15 \mathrm{mg} / \mathrm{L}$ hypoxanthine, $25 \mathrm{mg} / \mathrm{L}$ gentamycin, and $0.5 \%$ Albumax I in human $\mathrm{A}^{+}$erythrocytes. Cultures were incubated at $37^{\circ} \mathrm{C}$ in a humidified environment of $5 \% \mathrm{CO}_{2}$ and $95 \%$ air.

\subsection{Antiplasmodium Activity Assay}

A SyBR green I-based fluorescent assay which measures the DNA content of the parasite was used to measure inhibitory property of extracts [20-22]. The dried extracts were reconstituted in $100 \%$ DMSO or ethanol, and were serially diluted in culture medium as needed and added to the parasite culture (Dd2 line) at 1\% parasitemia and 1\% hematocrit in 96-well black plates (Greiner Bio-One, Monroe, NC, USA). The final concentration of the vehicles in the assay did not exceed $0.2 \%$, which was used as a negative control. Following incubation for $72 \mathrm{~h}$ at $37^{\circ} \mathrm{C}$ the plates were frozen at $-80^{\circ} \mathrm{C}$ and thawed. Lysis buffer $(20 \mathrm{mM}$ Tris- $\mathrm{HCl}, 0.08 \%$ saponin, $5 \mathrm{mM}$ EDTA, $0.8 \%$ Triton $\mathrm{X}-100$, and $0.01 \%$ SYBR Green I) was added to each well and incubated in the dark for $30 \mathrm{~min}$ at $37^{\circ} \mathrm{C}$. Fluorescence emission from the wells was measured using a Synergy H4 multimode plate reader (Biotek, Winooski, VT, USA) at wavelengths $485 \mathrm{nM}$ for excitation and $530 \mathrm{nM}$ for emission.

\subsection{Cytotoxicity Assay}

Dilutions of extracts were evaluated for cytotoxicity [23] in mouse $3 \mathrm{~T} 3$ fibroblast cells (2500 cells/well) in 384 well clear bottom plates (Santa Cruz Biotechnology, Dallas, TX, USA). The plates were incubated for $48 \mathrm{~h}$ at $37{ }^{\circ} \mathrm{C}$ in a humidified environment $\left(5 \% \mathrm{CO}_{2}, 95 \%\right.$ air). Following the incubation period $20 \mu \mathrm{L}$ MTS ((3-(4,5-dimethylthiazol-2-yl)-5-(3-carboxymethoxyphenyl)2-(4-sulfophenyl)-2H-tetrazolium), CellTiter $96^{\circledR}$ Aqueous nonradioactive cell proliferation assay, Promega) reagent was added to each well, the plates were further incubated for an additional $3 \mathrm{~h}$. Cell viability data were obtained by measuring absorbance at $490 \mathrm{~nm}$ using Synergy H4 plate reader (Biotek, Winooski, VT, USA). 


\subsection{Dereplication of Bioactive Fractions}

V324, KJ1233. The methanol extract (151 mg) from V324 (KJ1233) was chromatographed using medium performance liquid chromatography (MPLC) using a Combiflash ${ }^{\mathrm{TM}} \mathrm{RF} x 4$ flash chromatography instrument (Teledyne Isco, Lincoln NE). The sample was bound to C-18 packing, packed in a loading cartridge and then chromatographed on a $4.3 \mathrm{~g}$ RediSep Gold C-18 column using a gradient from $\mathrm{H}_{2} \mathrm{O}: \mathrm{CH}_{3} \mathrm{CN}$ (9:1) to $100 \%$ acetonitrile over 32 column volumes (CV), followed by isocratic $\mathrm{CH}_{3} \mathrm{CN}$ for $10 \mathrm{CV}$ then washed with methanol for $4 \mathrm{CV}$ and then a methanol to $100 \%$ dichloromethane wash over $12 \mathrm{CV}$. The flow rate was $18 \mathrm{~mL} / \mathrm{min}$. The resulting material was collected into 44 tubes, which were then combined into 12 fractions based upon observed peaks at $220 \mathrm{~nm}$ and $254 \mathrm{~nm}$. The fractions were dried down through distillation under reduced pressure, transferred into pre-weighed vials, and brought up into $10 \mathrm{mg} / \mathrm{mL}$ solutions for analysis and subsampling for bioassay.

V881, KJ1242. The methanol extract (515 mg) from V881, (KJ1242) was chromatographed using medium performance liquid chromatography (MPLC) using a Combiflash ${ }^{\mathrm{TM}} \mathrm{RFx} 4$ flash chromatography instrument (Teledyne Isco, Lincoln, NE). The sample was bound to C-18 packing, packed in a loading cartridge and then chromatographed on a 13 g RediSep Gold C-18 column using a gradient from $\mathrm{H}_{2} \mathrm{O}: \mathrm{CH}_{3} \mathrm{CN}$ (95:5) to $100 \%$ acetonitrile over 20 column volumes $(\mathrm{CV})$, followed by isocratic $\mathrm{CH}_{3} \mathrm{CN}$ for $5 \mathrm{CV}$ then washed with methanol for $2.5 \mathrm{CV}$ and then a methanol to $100 \%$ dichloromethane wash over $6 \mathrm{CV}$. The flow rate was $30 \mathrm{~mL} / \mathrm{min}$. The resulting material was collected into 71 tubes, which were then combined into 10 fractions based upon observed peaks at $220 \mathrm{~nm}$ and $280 \mathrm{~nm}$. The fractions were dried down through distillation under reduced pressure, transferred into pre-weighed vials, and brought up into $10 \mathrm{mg} / \mathrm{mL}$ solutions for analysis and subsampling for bioassay.

\section{Results}

\subsection{Extracts of Marine Microbes Used in Screening}

A library of 2365 marine microbial extracts was prepared from the HBMMCC. These were derived from 694 isolates from the HBMMCC: 316 fungi (F), 45 actinomycetes (A) and 332 other bacteria (157 gram-negative (B (G-)) and 175 gram-positive B (G+)). For this work we used a variety of fermentation conditions: $46.6 \%$ of the extracts were from SYZ shake cultures; $25.8 \%$ from KP shake cultures; $26.0 \%$ from moistened rice cultures; $0.8 \%$ from static SYZ cultures; and $0.8 \%$ from static KP cultures. The average extract yield was $130 \mathrm{mg}$ (range 50-300 mg) and provided sufficient material for both screening and preliminary chemical studies.

\subsection{Screening of HBMCC Extracts for Antiplasmodial Activities}

We used SYBR green I-based fluorescence assay which measures inhibition of growth in terms of reduction in DNA content to measure antiplasmodial activities of marine microbial extracts. Initial screening of 2365 diverse marine microbial extracts was carried out at a concentration of $10 \mu \mathrm{g} / \mathrm{mL}$ using the chloroquine-resistant Dd2 strains under standard culture conditions [24] for $72 \mathrm{~h}$. For our primary screen, we used the chloroquine-resistant Dd2 strain as our main goal is to overcome the problem of drug-resistant malaria. All plates contained control wells: (a) culture only and (b) with chloroquine. $\mathrm{Z}^{\prime}$ factor, which is a statistical parameter of assay quality [25] was calculated and only those assays with values $>0.7$ were considered for evaluation. An extract was considered as a potential "hit" when it exhibited at least $70 \%$ inhibition of growth at $10 \mu \mathrm{g} / \mathrm{mL}$. Extracts exhibiting $\geq 70 \%$ inhibition were subjected to screening at $1 \mu \mathrm{g} / \mathrm{mL}$; Figure $1 \mathrm{~A}$ shows the active extracts with $\geq 50 \%$ inhibition at $1 \mu \mathrm{g} / \mathrm{mL}$. The extracts active $\leq 1 \mu \mathrm{g} / \mathrm{mL}$ were subjected to $\mathrm{EC}_{50}$ determination (Figure $1 \mathrm{~B}$ ).

We also determined the cytotoxicity of active fractions against NIH 3T3 fibroblasts using an MTS cell proliferation assay [23]. As can be seen from Table 2, 17 fractions from diverse microbial sources exhibited promising activities with $\mathrm{EC}_{50}$ values $\leq 1 \mu \mathrm{g} / \mathrm{mL}$ It is to be noted that active fractions also have good selectivity of $>10$. 


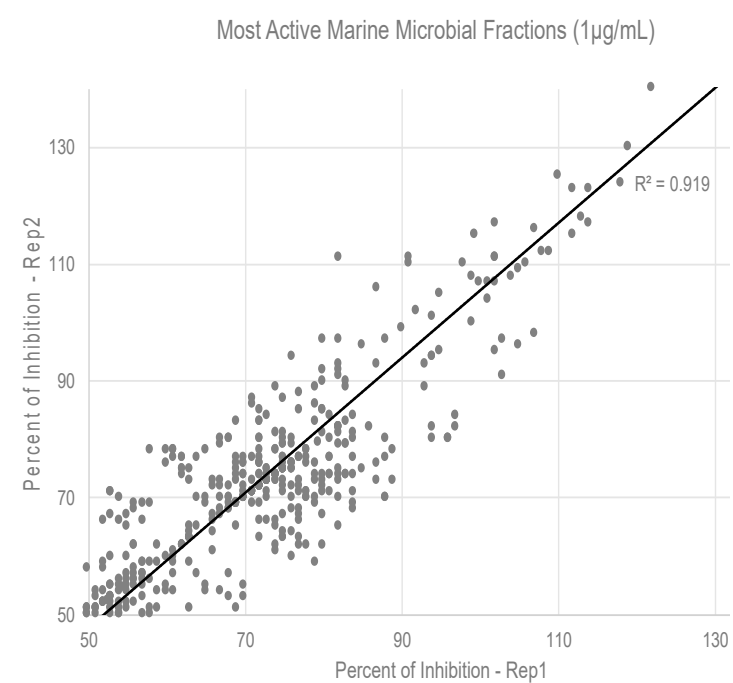

(A)

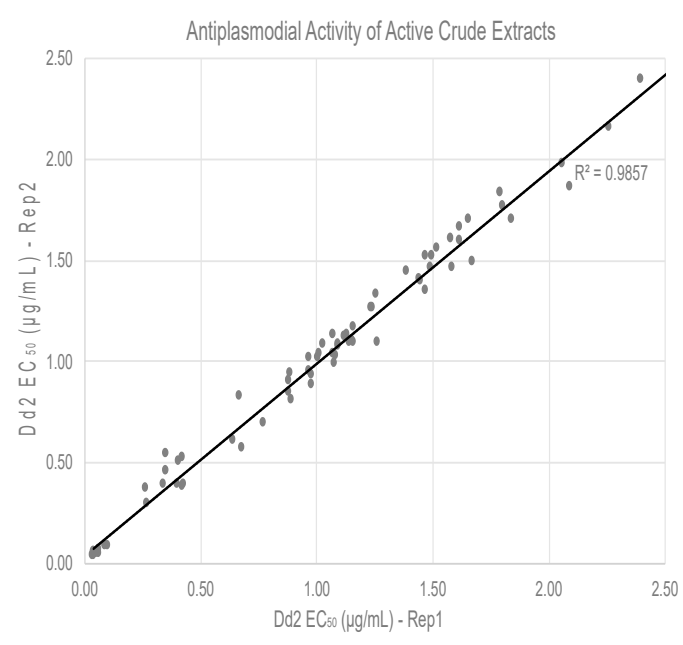

(B)

Figure 1. Antiplasmodial activities of marine microbial extracts. (A) Active extracts with $\geq 50 \%$ inhibition at $1 \mu \mathrm{g} / \mathrm{mL}$. Percent inhibition of P. falciparum Dd2 growth in two different replicates (Rep1 and Rep2) of SYBR green-I fluorescence assay is shown in a correlation plot. (B) Fifty percent inhibitory concentrations (EC50) of top hit extracts are shown.

Table 2. Activity of promising extracts.

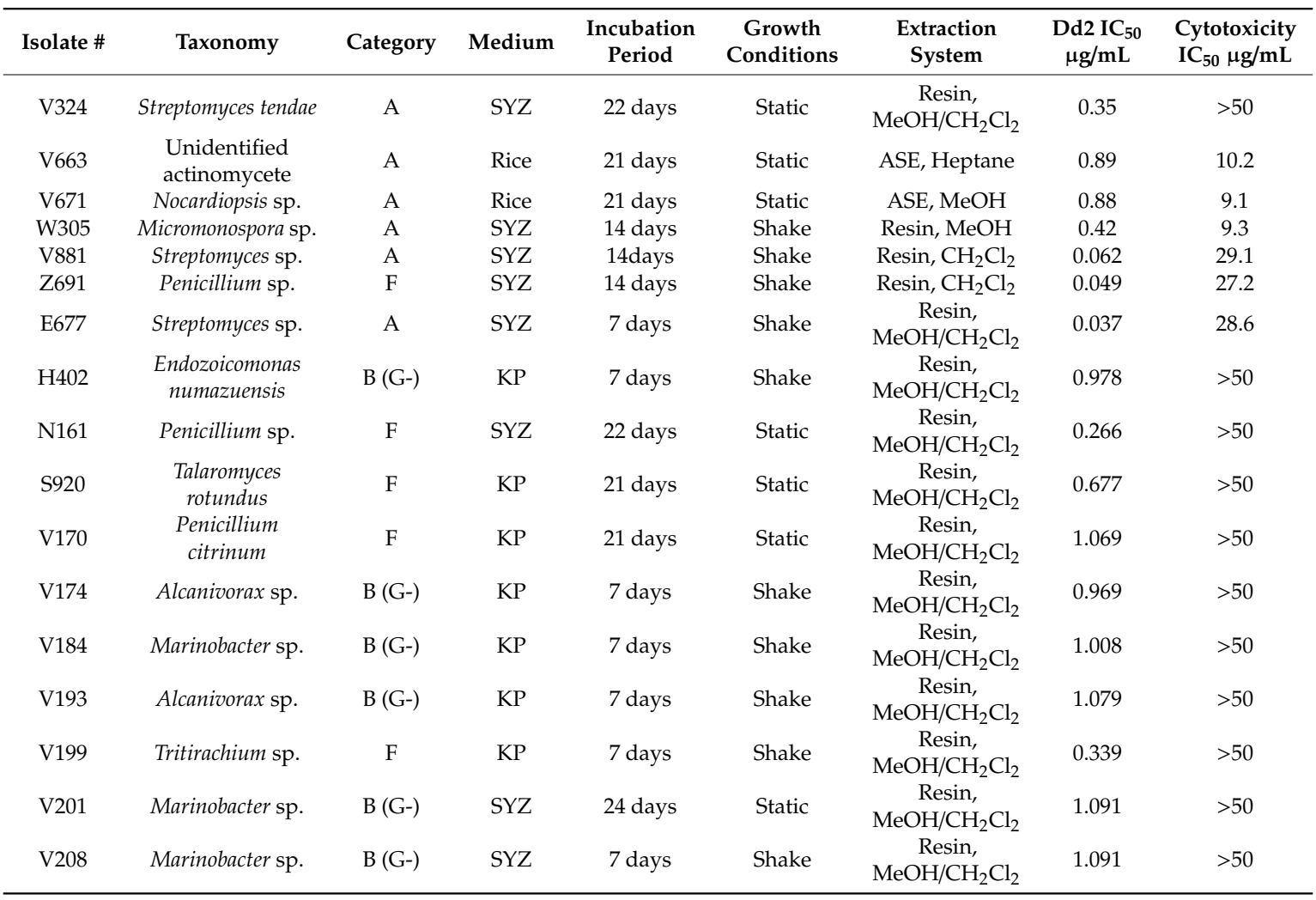

\subsection{Identification of Bioactive Compounds}

Isolates V324 and V881. The first sample that was investigated was the methanol extract from V324, extract ID: KJ1233. MPLC fractionation yielded three active fractions, which upon interpretation of the NMR spectra suggested that they appear to be mixtures of phosphatidyl choline analogs. Full 
structure characterization was not conducted, as this class of compound is known to show strong antiplasmodial activity [26].

The second sample that was investigated was organism V881, extract ID: KJ1242. The active extract exhibited a promising $\mathrm{EC}_{50}$ of $0.062 \mu \mathrm{g} / \mathrm{mL}$. MPLC fractionation yielded ten fractions. The ${ }^{1} \mathrm{H}$ NMR spectra of the most potent fractions were complex with large resonances attributable to lipids and other very minor components with aromatic, olefinic and hetero substituted methine resonances. The LC-MS signal was also complex showing the presence of multiple compounds. The fraction was a light purple in color and a number of HPLC separations were attempted on different C-18 and amino substituted stationary phases. In all cases it appeared that the purple compound was associated with bioactivity but it was present in very low amounts. This compound also showed unusual chromatography in that at times it appeared quite polar and at other times less polar. Unfortunately, the active compound was never fully purified, and its structure remains to be identified. Further work including large scale up of the culture is required to fully identify the structure of the compound.

\section{Discussion}

This project screened a subset of the Harbor Branch Marine Microbial Culture Collection for antiplasmodial activity. Of the 2365 extracts tested, 317 (13\%) exhibited 70\% inhibition when tested at $1 \mu \mathrm{g} / \mathrm{mL}$ (Figure 1). From these preliminary hits we were able to identify 17 extracts which could be considered leads based on their inhibitory activity against the chloroquine-resistant $P$. falciparum and their cytotoxicity towards mammalian cells. The leads were produced from actinomycetes, fungi and gram-negative bacteria. Interestingly, no non-actinomycete gram-positive bacteria were found to be leads even though they comprised over $25 \%$ of the isolates tested. The leads came from both KP and SYZ liquid fermentations with no overlap between the two media even though many isolates were grown on both media. It is most interesting that $5 / 17$ leads were generated from static liquid cultures even though only $1.6 \%$ of the extracts came from this type of fermentation.

The leads that were generated by this project came from a broad range of taxa. The five fungal isolates were Penicillium spp., Talaromyces rotundus, which was considered a teleomorph of Penicillium but is now considered a distinct phylogenetic lineage [27], and Tritirachium sp. There is an extensive literature on the natural products of terrestrial Penicillium and other fungi [28]; however, recently, marine isolates from these genera have proven to be the source of novel natural products [18]. The same is true for Talaromyces spp., which are common mangrove endophytes and which have been shown to produce a broad range of natural products $[18,29]$. Marine strains of Tritirachium have also received attention for their production of natural products, including xanthoquinodin-like compounds from a Tritirachium isolated from a marine sponge [30].

The six strains of actinomycetes that showed activities are also not unexpected as, in general, these gram-positive bacteria are prolific producers of bioactive natural products [31]. It was, however, surprising to find that six isolates of gram-negative bacteria showed activity in our screen. Gram-negative bacteria have recently been recognized as a potentially valuable resource for the discovery of natural products including polyketides, nonribosomal peptides, hybrid polyketide-nonribosomal peptides and others [32]. Three of our active isolates belong to the genus Marinobacter, which has been found to produce the siderophore petrobactin [33]. However, other natural products and their biological activity have not been reported. The oil-degrading bacterium Alcanivorax is known to produce surfactants [34] as well as the $\alpha$-pyrone alcanivorone [35] but no biological activity has been reported for this molecule. Endozoicomonas spp. are known to be associated with tunicates [36], sponges [37], and octocorals [38], where they can become dominant members of the microbial community. There have been no studies of their secondary metabolites but one paper described antibacterial activity of Endozoicomonas extracts [37].

Our initial attempt to identify the structure of bioactive component of V881 was inconclusive. We now recognize the interference of commonly encountered compounds such as fatty acids and 
choline derivatives that will have to be dereplicated early in the discovery process in order to find the more structurally complex natural products with potential for development as pharmaceutical agents.

Our results support the hypothesis that marine microorganisms have a very high likelihood of yielding novel antimalarial chemotypes. From the isolates producing high levels of activity we have found taxonomic diversity, which we expect to translate into chemical diversity with continued study. Based on the taxonomy of the producing organisms we expect to find novel chemotypes from this ongoing project.

Author Contributions: D.C., P.M. and A.W. conceptualized the project. P.M. selected the microbes for fermentation and provided oversight for the production of extracts. B.R. and A.C. performed the anti-plasmodial bioassays. D.C. provided oversight for the anti-plasmodial assays and was responsible for the selection of hits. J.R. performed the isolation of bioactive compounds. A.W. provided oversight for the isolation of bioactive compounds. D.C., P.M. and A.W. secured funding for the project and provided administrative oversight. D.C., P.M. and A.W. wrote, reviewed and edited the manuscript.

Funding: The work was supported by a grant from NIH AI100280.

Conflicts of Interest: The authors declare no conflict of interest.

\section{References}

1. WHO. World Malaria Report; World Health Organization: Geneva, Switzerland, 2018.

2. Ashley, E.A.; Dhorda, M.; Fairhurst, R.M.; Amaratunga, C.; Lim, P.; Suon, S.; Sreng, S.; Anderson, J.M.; Mao, S.; Sam, B.; et al. Spread of artemisinin resistance in Plasmodium falciparum malaria. N. Engl. J. Med. 2014, 371, 411-423. [CrossRef] [PubMed]

3. Nsanzabana, C. Resistance to Artemisinin Combination Therapies (ACTs): Do Not Forget the Partner Drug! Trop. Med. Infect. Dis. 2019, 4, 26. [CrossRef]

4. Newman, D.J.; Cragg, G.M. Natural Products as Sources of New Drugs from 1981 to 2014. J. Nat. Prod. 2016, 79, 629-661. [CrossRef] [PubMed]

5. Molinski, T.F.; Dalisay, D.S.; Lievens, S.L.; Saludes, J.P. Drug development from marine natural products. Nat. Rev. Drug Dis. 2009, 8, 69-85. [CrossRef] [PubMed]

6. Mayer, A.M.; Glaser, K.B.; Cuevas, C.; Jacobs, R.S.; Kem, W.; Little, R.D.; McIntosh, J.M.; Newman, D.J.; Potts, B.C.; Shuster, D.E. The odyssey of marine pharmaceuticals: A current pipeline perspective. Trends Pharmacol. Sci. 2010, 31, 255-265. [CrossRef] [PubMed]

7. Giovannoni, S.J.; Stingl, U. Molecular diversity and ecology of microbial plankton. Nature 2005, 437, 343-348. [CrossRef]

8. Gloeckner, V.; Wehrl, M.; Moithinho-Silva, L.; Gernert, C.; Schupp, P.; Pawlick, J.R.; Lindquist, N.L.; Erpenbeck, D.; Worheide, G.; Hentschel, U. The HMA-LMA Dichotomy Revisited: An Electron Microscopical Survey of 56 Sponge Species. Biol. Bull. 2014, 227, 78-88. [CrossRef] [PubMed]

9. Konig, G.M.; Kehraus, S.; Seibert, S.F.; Abdel-Lateff, A.; Muller, D. Natural products from marine organisms and their associated microbes. Chembiochem 2006, 7, 229-238. [CrossRef]

10. Lackner, G.; Peters, E.E.; Helfrich, E.J.; Piel, J. Insights into the lifestyle of uncultured bacterial natural product factories associated with marine sponges. Proc. Natl. Acad. Sci. USA 2017, 114, E347-E356. [CrossRef]

11. Rao, K.V.; Kasanah, N.; Wahyuono, S.; Tekwani, B.L.; Schinazi, R.F.; Hamann, M.T. Three new manzamine alkaloids from a common Indonesian sponge and their activity against infectious and tropical parasitic diseases. J. Nat. Prod. 2004, 67, 1314-1318. [CrossRef]

12. Waters, A.L.; Peraud, O.; Kasanah, N.; Sims, J.W.; Kothalawala, N.; Anderson, M.A.; Abbas, S.H.; Rao, K.V.; Jupally, V.R.; Kelly, M.; et al. An analysis of the sponge Acanthostrongylophora igens' microbiome yields an actinomycete that produces the natural product manzamine A. Front. Mar. Sci. 2014, 1. [CrossRef] [PubMed]

13. Bultel-Ponce, V.V.; Berge, J.P.; Debitus, C.; Nicolas, J.L.; Guyot, M. Metabolites from the Sponge-Associated Bacterium Pseudomonas Species. Mar. Biotechnol. (N. Y.) 1999, 1, 384-390. [CrossRef]

14. Matsumoto, K.; Choshi, T.; Hourai, M.; Zamami, Y.; Sasaki, K.; Abe, T.; Ishikura, M.; Hatae, N.; Iwamura, T.; Tohyama, S.; et al. Synthesis and antimalarial activity of calothrixins A and B, and their N-alkyl derivatives. Bioorg. Med. Chem. Lett. 2012, 22, 4762-4764. [CrossRef] [PubMed]

15. Olson, J.B.; Lord, C.C.; McCarthy, P.J. Improved Recoverability of Microbial Colonies from Marine Sponge Samples. Microb. Ecol. 2000, 40, 139-147. [CrossRef] [PubMed] 
16. Sfanos, K.; Harmody, D.; Dang, P.; Ledger, A.; Pomponi, S.; McCarthy, P.; Lopez, J. A molecular systematic survey of cultured microbial associates of deep-water marine invertebrates. Syst. Appl. Microbiol. 2005, 28, 242-264. [CrossRef] [PubMed]

17. Gunasekera, A.S.; Sfanos, K.S.; Harmody, D.K.; Pomponi, S.A.; McCarthy, P.J.; Lopez, J.V. HBMMD: An enhanced database of the microorganisms associated with deeper water marine invertebrates. Appl. Microbiol. Biotechnol. 2005, 66, 373-376. [CrossRef] [PubMed]

18. Nicoletti, R.; Trincone, A. Bioactive Compounds Produced by Strains of Penicillium and Talaromyces of Marine Origin. Mar. Drugs 2016, 14, 37. [CrossRef]

19. Trager, W.; Jensen, J.B. Human malaria parasites in continuous culture. Science 1976, 193, 673-675. [CrossRef]

20. Bennett, T.N.; Paguio, M.; Gligorijevic, B.; Seudieu, C.; Kosar, A.D.; Davidson, E.; Roepe, P.D. Novel, rapid, and inexpensive cell-based quantification of antimalarial drug efficacy. Antimicrob. Agents Chemother. 2004, 48, 1807-1810. [CrossRef]

21. Johnson, J.D.; Dennull, R.A.; Gerena, L.; Lopez-Sanchez, M.; Roncal, N.E.; Waters, N.C. Assessment and continued validation of the malaria SYBR green I-based fluorescence assay for use in malaria drug screening. Antimicrob. Agents Chemother. 2007, 51, 1926-1933. [CrossRef]

22. Smilkstein, M.; Sriwilaijaroen, N.; Kelly, J.X.; Wilairat, P.; Riscoe, M. Simple and inexpensive fluorescence-based technique for high-throughput antimalarial drug screening. Antimicrob. Agents Chemother. 2004, 48, 1803-1806. [CrossRef] [PubMed]

23. Gupta, P.B.; Onder, T.T.; Jiang, G.; Tao, K.; Kuperwasser, C.; Weinberg, R.A.; Lander, E.S. Identification of selective inhibitors of cancer stem cells by high-throughput screening. Cell 2009, 138, 645-659. [CrossRef] [PubMed]

24. Jensen, J.B. In vitro culture of Plasmodium parasites. Methods Mol. Med. 2002, 72, 477-488. [CrossRef] [PubMed]

25. Zhang, J.H.; Chung, T.D.; Oldenburg, K.R. A Simple Statistical Parameter for Use in Evaluation and Validation of High Throughput Screening Assays. J. Biomol. Screen 1999, 4, 67-73. [CrossRef] [PubMed]

26. Peyrottes, S.; Caldarelli, S.; Wein, S.; Perigaud, C.; Pellet, A.; Vial, H. Choline analogues in malaria chemotherapy. Curr. Pharm. Des. 2012, 18, 3454-3466. [CrossRef]

27. Houbraken, J.; Samson, R.A.; Yilmaz, N. Taxonomy of Aspergillus, Penicillium and Talaromyces and Its Significance for Biotechnology. In Aspergillus and Penicillium in the Post-Genomic Era; Caister Academic Press: Norfolk, UK, 2016.

28. Nielsen, J.C.; Grijseels, S.; Prigent, S.; Ji, B.; Dainat, J.; Nielsen, K.F.; Frisvad, J.C.; Workman, M.; Nielsen, J. Global analysis of biosynthetic gene clusters reveals vast potential of secondary metabolite production in Penicillium species. Nat. Microbiol. 2017, 2, 17044. [CrossRef] [PubMed]

29. Nicoletti, R.; Salvatore, M.M.; Andolfi, A. Secondary Metabolites of Mangrove-Associated Strains of Talaromyces. Mar. Drugs 2018, 16, 12. [CrossRef]

30. Ueda, J.Y.; Takagi, M.; Shin-ya, K. New xanthoquinodin-like compounds, JBIR-97, -98 and -99 , obtained from marine sponge-derived fungus Tritirachium sp. SpB081112MEf2. J. Antibiot. (Tokyo) 2010, 63, 615-618. [CrossRef]

31. Barka, E.A.; Vatsa, P.; Sanchez, L.; Gaveau-Vaillant, N.; Jacquard, C.; Meier-Kolthoff, J.P.; Klenk, H.P.; Clement, C.; Ouhdouch, Y.; van Wezel, G.P. Taxonomy, Physiology, and Natural Products of Actinobacteria. Microbiol. Mol. Biol. Rev. 2016, 80, 1-43. [CrossRef]

32. Masschelein, J.; Jenner, M.; Challis, G.L. Antibiotics from Gram-negative bacteria: A comprehensive overview and selected biosyntheitic highlights. Nat. Prod. Rep. 2017, 34, 712-783. [CrossRef]

33. Homann, V.V.; Edwards, K.J.; Webb, E.A.; Butler, A. Siderophores of Marinobacter aquaeolei: Petrobactin and its sulfonated derivatives. Biometals 2009, 22, 565-571. [CrossRef] [PubMed]

34. Yakimov, M.M.; Golyshin, P.N.; Lang, S.; Moore, E.R.B.; Abraham, W.-R.; Lünsdorf, H.; Timmis, K.N. Alcanivorax borkumensis gen. nov., sp. nov., a new, hydrocarbon-degrading and surfactant-producing marine bacterium. Int. J. Syst. Evol. Microbiol. 1998, 48, 339-348. [CrossRef] [PubMed]

35. Kanoh, K.; Adachi, K.; Katsuta, A.; Shizuri, Y. Structural determination and proposed biosynthesis of alcanivorone, a novel a-pyrone produced by Alcanivorax jadensis. J. Antibiotics 2008, 61, 70-74. [CrossRef]

36. Bayer, T.; Neave, M.J.; Alsheikh-Hussain, A.; Aranda, M.; Yum, L.K.; Mincer, T.; Hughen, K.; Apprill, A.; Voolstra, C.R. The Microbiome of the Red Sea Coral Stylophora pistillata Is Dominated by Tissue-Associated Endozoicomonas Bacteria. Appl. Environ. Microbiol. 2013, 79, 4759-4762. [CrossRef] [PubMed] 
37. Rua, C.P.J.; Trindade-Silva, A.E.; Appolinario, L.R.; Venas, T.M.; Garcia, G.D.; Carvalho, L.S.; Lima, A.; Kruger, R.; Pereira, R.C.; Berlinck, R.G.S.; et al. Diversity and antimicrobial potential of culturable heterotrophic bacteria associated with the endemic marine spongeArenosclera brasiliensis. PeerJ 2014, 2 , e419. [CrossRef] [PubMed]

38. Pike, R.E.; Haltli, B.; Kerr, R.G. Description of Endozoicomonas euniceicola sp. nov. and Endozoicomonas gorgoniicola sp. nov., bacteria isolated from the octocorals Eunicea fusca and Plexaura sp., and an emended description of the genus Endozoicomonas. Int. J. Syst. Evol. Microbiol. 2013, 63, 4294-4302. [CrossRef]

(C) 2019 by the authors. Licensee MDPI, Basel, Switzerland. This article is an open access article distributed under the terms and conditions of the Creative Commons Attribution (CC BY) license (http://creativecommons.org/licenses/by/4.0/). 